\title{
Aberrations in Nicotinic Acetylcholine Receptor Structure, Function, and Expression: Implications in Disease
}

\author{
Frank Salamone ${ }^{* \dagger}$, B.S., M.D. and Ming Zhou ${ }^{\dagger}$, B.S., Ph.D.
}

\section{INTRODUCTION}

Much of modern pharmacology is concerned with receptors that are present in the plasma membrane of cells. Physicians are familiar with the dopaminergic hypothesis of schizophrenia, the implication of aminergic receptor dysfunction in depression, and the role of $\mathrm{H} 2$ receptors in stomach acid production. The relationship between nicotinic acetylcholine receptors (nAChR) and disease is not as well known, although these proteins have been studied extensively. The goal of this review is to introduce the reader to the $\mathrm{nAChR}$, as well as to describe how aberrations in its structure, function, and expression may be involved in the pathophysiology of a number of disease states including autosomal dominant nocturnal frontal lobe epilepsy (ADNFLE), the slow channel congenital myasthenic syndromes (SCCMS), Alzheimer's disease (AD), and schizophrenia.

\section{THE NICOTINIC ACETYLCHOLINE RECEPTOR}

\section{Structure and Function}

Nicotinic acetylcholine receptors comprise a class of pentameric (containing five subunits) ligand-gated ion channels present in the central and peripheral nervous systems (Figure 1A) (1-3). Based on several lines of evidence, each receptor subunit can be functionally and structurally divided into a number of domains (Figure

\footnotetext{
* To whom correspondence should be addressed: Department of Otolaryngology - Head and Neck Surgery, Univeristy of Cincinnati, PO Box 670528, Cincinnati OH 45267-0528 USA. E-mail: fns99@yahoo.com.

$\dagger$ Department of Physiology and Biophysics, State University of New York at Buffalo, Buffalo, New York.
}

1B). The N-terminal region of the protein is exposed to the extracellular space and contains the ligand-binding domain in certain subunits (see below). Proceeding from this domain towards the C-terminus, the peptide chain is believed to traverse the lipid bilayer four times and both ends of the protein therefore face the extracellular space (3). The second transmembrane domain (M2) lines the channel pore, and its amino acids determine the channel's ionic selectivity (4).

Although highly homologous, nAChR of the periphery and the central nervous system (CNS) differ in some key aspects. The adult-type neuromuscular variant of the channel is present exclusively in the cell membrane of skeletal muscle and consists of two copies of the $\alpha 1$ subunit - each of which contains a single ligand binding domain - along with one $\beta$, one $\delta$, and one $\varepsilon$ subunit (3).

Neuronal nAChR found in the central nervous system and in autonomic ganglia are pentamers of $\alpha$ and $\beta$ subunits that have a different primary structure than those of the periphery (5). Eight putative neuronal $\alpha$ subunit genes (labeled $\alpha 2-\alpha 9$ ) have been found that are homologous to the muscle $\alpha 1$ subunit and probably contain ligand-binding domains (for a detailed review of neuronal nicotinic acetylcholine receptors, see reference 6). Neuronal $\beta$ subunits (three of which have been cloned) show less homology to neuromuscular $\beta$ subunits, but were thus named because they do not have an adjacent pair of cystines present in the $\alpha$ subunit ligand-binding region (5).

When expressed heterologously in oocytes, combinations of neuronal $\alpha$ and $\beta$ subunits form functional channels whose properties depend on the particular subunits injected (7). Most receptors require 
A

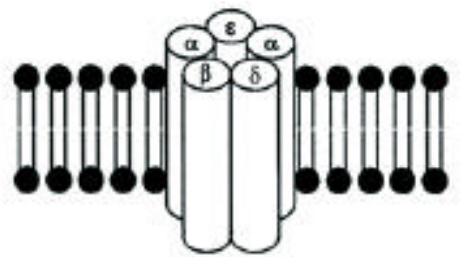

B

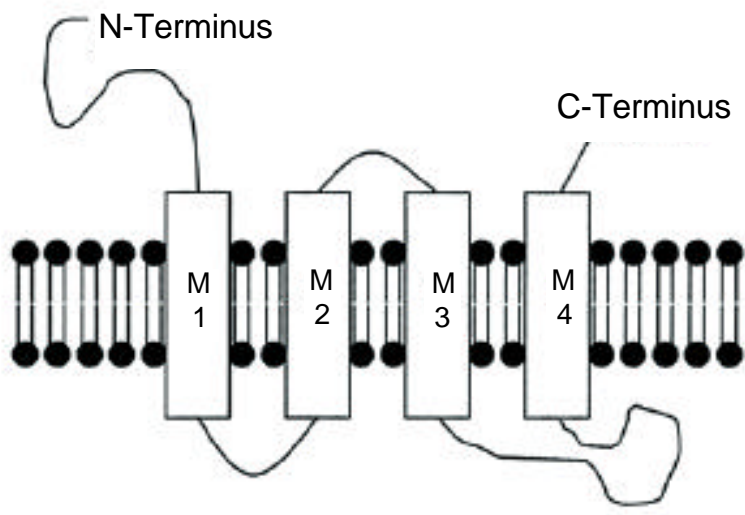

Figure 1. Views of the nicotinic acetylcholine receptor. A: Schematic representation of receptor as it appears in the plasma membrane. Five protein subunits, each spanning the lipid bilayer, come together to form a pore through the cell membrane. The pore through which ions can travel is seen in the middle of the structure. Greek letters denote the four different types of subunits that exist; a functional channel is composed of a combination of different subunit types (see text). B: Transmembrane topology of a single subunit of the nicotinic acetylcholine receptor. The subunit is shown stretched out in order to see the individual domains, though in reality the structure is more compact and corresponds to an individual cylinder in the representation seen in part A. Transmembrane domains are labeled M1-M4. The large N-terminal domain contains the ligand-binding domain in $\alpha$ subunits and faces the synaptic cleft. The M2 domain faces the inside of the channel pore and determines the ionic selectivity based on its amino acid composition.

co-expression of $\alpha$ and $\beta$ subunits (for example $\alpha 4$ and $\beta 2$ ), though $\alpha 7$ and $\alpha 8$ subunits can form functional homooligomers (8-11). Although the many subunits available from the genetic stock allow for receptors with a rich functional diversity, the need for this or actual occurrence of such a large number of combinations in the brain is open to question (12).

Functionally, when agonists bind to the nAChR, the protein undergoes a global change in three-dimensional structure causing the channel gate to open (13). This allosteric transition to the "open state" of the receptor allows the passage of ions through the pore. The agonist may also dissociate from the receptor. When confronted with agonist for a long period of time, the receptor enters a family of desensitized states in which the ligand is bound tightly but the channel is non-conducting (14). The receptor may lose agonist with a certain probability and escape from the desensitized state to begin opening again. For the sake of this review, receptor function will be discussed in terms of binding, un-binding, opening, closing, and desensitization (Figure 2). This view is certainly a simplification as each grossly observable state may consist of many protein conformations.

Calcium is a particularly important ion with respect to intracellular signaling. Both neuromuscular and neuronal receptors are permeable to this cation, although the flux is much higher for the neuronal protein. Nicotinic receptor calcium flux, according to Vernino et al., may be important in synaptic development, maintenance and plasticity (15). In addition, receptor mutations that alter calcium flux may cause disease by altering signal pathways or by the direct toxicity of this ion (16).

\section{Nicotinic Receptors in the Brain}

Neuronal nAChRs in the brain identified autoradiographically can be divided into two types: those that bind ${ }^{3} \mathrm{H}$-labeled agonists such as nicotine and $\mathrm{ACh}$ $\left({ }^{3} \mathrm{H}\right.$ sites) and those that bind ${ }^{125}$ I-labeled $\alpha$ Bungarotoxin ( $\alpha$-Btx sites) (6). The $\alpha 4 \beta 2$ receptors account for most of the ${ }^{3} \mathrm{H}$-labeled agonist binding while the $\alpha 7$ homooligomers account for most of the $\alpha$-Btx binding (17). Anatomically, ${ }^{3} \mathrm{H}$ sites are primarily located in regions of the thalamus, neocortex and striatum while $\alpha$-Btx sites are located in the hippocampus and portions of the neocortex (6). In terms of neuronal pathways, the cholinergic systems most important to this discussion are those of the magnocellular basal complex. This system originally described by Meynert and further classified by Mesulam - provides for rich cortical innervation. Mesulam identified eight cell groups (Ch1-8) of which Ch4 is associated with the nucleus basalis of Meynert. This nucleus innervates frontal, parietal, and occipital cortex and undergoes degeneration in Alzheimer's disease $(6,18)$.

The precise location of neuronal $\mathrm{nAChR}$ relative to the synapse is not known. McGehee et al. - citing that in spite of the fact that there are abundant ${ }^{3} \mathrm{H}$ sites in the CNS, no one has conclusively demonstrated a functioning nicotinic synapse in the brain - argue for a presynaptic, modulatory role for the neuronal nicotinic receptor (19). Nanomolar concentrations of nicotine enhance release of the excitatory neurotransmitter glutamate into the synapses between the cells of the medial habenular nucleus and the interpeduncular nucleus. Thus, nicotine can modify synaptic transmission without being the primary molecule of chemical-electrical transduction. On the other hand, a postsynaptic location is indicated by indirect evidence. Ganglion cells, which contain neuronal nicotinic receptors, form functioning nicotinic synapses, and therefore, by extension, such an arrangement is possible in the brain (17). Also, cells taken from the rat medial habenula exhibit currents when patch clamped and 


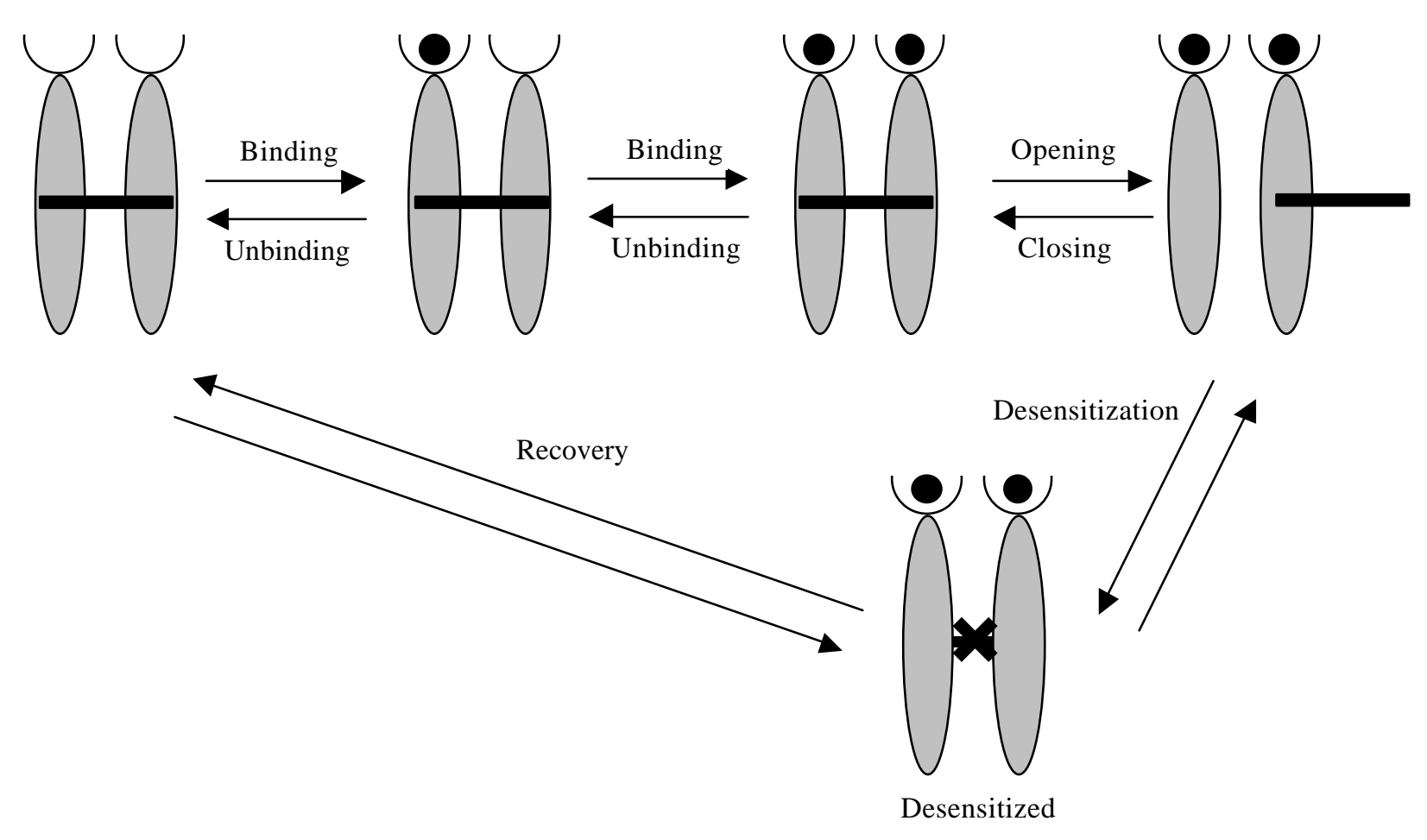

Figure 2. Allosteric states of the nicotinic acetylcholine receptor (modified from figure 10 in ref. 14). When the receptor binds agonist its global conformation changes. After binding two molecules of agonist, the protein may enter a conducting conformation. The open channel may adopt a desensitized state in which the channel is non-conducting and the agonist is bound with high affinity.

exposed to nicotinic agonists. Clearly, much remains to be learned about the functioning of the $\mathrm{nAChR}$ in the brain, and understanding the role of the $\mathrm{nAChR}$ within the context of the neural circuit will be important for explaining the clinical manifestations of disease.

\section{ABERRATIONS IN NICOTINIC ACETYL- CHOLINE RECEPTOR STRUCTURE AND FUNCTION}

As stated previously, the nAChR may exist in a number of states with different observable properties (e.g. open and closed) and it may interchange between these states with a certain probability. Recently, mutations have been found in nAChRs that alter the probabilities of changes between states (e.g. the channel opens for longer periods of time or it desensitizes more rapidly) thereby changing receptor function and causing disease. Study of these mutations yields insight into the functioning of nicotinic receptors and allosteric proteins in general. These rare conditions also provide unique insight into how a defect in a single molecule contributes to the pathophysiology of disease.

\section{Autosomal Dominant Nocturnal Frontal Lobe Epilepsy}

Autosomal dominant nocturnal frontal lobe epilepsy (ADNFLE) is a rare condition characterized by partial seizures occurring mainly during the night and early morning (20). Patients, who often have no interictal epileptiform activity on EEG and have normal neurological examinations, are often misdiagnosed as suffering from other conditions such as sleep disorders. Ictal EEGs suggest frontal lobe dysfunction (21).

Genetic analysis shows linkage between chromosomal locus 20q13.2 and the ADNFLE phenotype (22). Interestingly, this region of the chromosome harbors the neuronal $\alpha 4$ subunit (CHRNA4) gene which is expressed in all layers of the frontal cortex. Sequencing of patients' CHRNA4 revealed a single nucleotide change causing an amino acid substitution in the critical, pore-lining M2 domain of the $\alpha 4$ subunit (see above) (23). Residues in this region are highly conserved among species, and mutations in the M2 domain cause drastic changes in channel properties, such as ion selectivity.

The activation properties of recombinant mutant (serine 247 phenylalanine) $\alpha 4$ subunits co-expressed with $\beta 2$ subunits in Xenopus oocytes have been studied. $\alpha 4-\mathrm{S} 247 \mathrm{~F}$ channels have a lower conductance, faster desensitization kinetics and slower recovery from desensitization than the wild type. In addition, calcium permeation through the receptor was much smaller than that of wild type (24). Intuitively, the bulky phenylalanine may block the ion permeation 
pathway and therefore decrease channel conduction. Although the relationship between the dysfunctional $\alpha 4$ subunit and ADNFLE is not clear, one possibility is that this mutation decreases the activity of inhibitory interneurons and therefore produces the typical hyperexcitability found in this type of epilepsy.

\section{Slow Channel Congenital Myasthenic Syndromes}

The slow channel congenital myasthenic syndromes (SCCMS) are diseases that clinically resemble myasthenia gravis, yet these patients have no nicotinic receptor autoantibodies (25). SCCMS are caused by mutations in the muscle type nAChR that alter its activation properties (26). Most SCCMS mutants yield receptors that remain open for abnormally long periods of time, even though these mutations are scattered throughout the protein. Thus, allelic diversity yields receptors that are functionally quite homogeneous. In addition to long open times, SCCMS mutants are activated more readily by choline than the wild type receptor (27). This basal activity, along with the prolonged channel open time, may cause increased calcium entry into the muscle cell with subsequent degradation of the neuromuscular junction typical of SCCMS.

The binding site mutation $\alpha \mathrm{G} 153 \mathrm{~S}$ yields long openings typical of the SCCMS mutants. Characterization of this mutant receptor in terms of its activation properties reveal that although the binding and opening rates for $\alpha \mathrm{G} 153 \mathrm{~S}$ are close to normal, the unbinding and closing rates are slowed (28). Thus, qualitatively, once agonist binds to the receptor, it binds for a longer period of time, increasing the probability of the receptor opening.

Within the $\alpha$ subunit, mutations found in the M1 $(\alpha \mathrm{N} 217 \mathrm{~K})$ and M2 ( $\alpha \mathrm{V} 249 \mathrm{~F})$ domains cause prolonged channel openings similar to those described above $(29,30)$. SCCMS mutations need not be in the $\alpha$ subunit. Mutants $\varepsilon \mathrm{L} 269 \mathrm{~F}$ and $\varepsilon$ T264P in the M2 domain of the $\varepsilon$ subunit, and mutant $\beta \mathrm{V} 266 \mathrm{M}$ in the $\beta$ subunit also yield SCCMS phenotypes $(31,32)$.

\section{ABERRATIONS IN NICOTINIC RECEPTOR DENSITY AND EXPRESSION}

Nicotinic receptors play a fundamental role in many brain pathways. Alterations in their density and expression have recently been implicated in Alzheimer's disease and schizophrenia. The pathophysiology of these conditions is less straightforward than that of ADNFLE and the SCCMS, and the contribution of the nAChR may not be the most significant inciting event. However, there is evidence that the $n A C h R$ does in fact play some role and, therefore, there is a possibility that this system can be therapeutically exploited.

\begin{abstract}
Alzheimer's Disease
Alzheimer's disease (AD) is a form of dementia affecting about $5-15 \%$ of the population over 65 years of age (33). Clinically this condition appears as a global decrease in functioning including deficits in recent memory, apraxia, and aphasia without changes in consciousness. In terms of pathophysiology, a key common pathway is the accumulation of neuritic plaques in the brain. These plaques are likely neurotoxic and lead to the destruction of nerve cells and eventually to dementia.
\end{abstract}

A number of groups have shown that nicotinic binding sites are reduced in the brains of AD patients. For example, Whitehouse et al. compared the brain ${ }^{3} \mathrm{H}$ binding of $19 \mathrm{AD}$ patients to that of 13 matched controls (34). The clinical diagnosis of AD was confirmed histopathologically in all 19 cases, and the controls had no clinical or histologically evident disease. Patients had significantly lower levels (in most cases on the order of a $50 \%$ reduction) of ${ }^{3} \mathrm{H} \mathrm{ACh}$ and ${ }^{3} \mathrm{H}(-)$ nicotine binding in their frontal, temporal and occipital cortices. Muscarinic receptors are largely preserved (33). Other studies show that levels of the enzyme choline acetyltransferase - necessary for the production of ACh - were reduced in the brains of those afflicted with AD $(33,35)$. Positron emission tomography (PET) allows visualization of changes in brain neurotransmitter binding in living subjects. It has been found that those with AD (as opposed to controls) have lower ${ }^{11} \mathrm{C}(-)$ nicotine binding in their frontal and temporal cortices, and that the severity of this deficit measured in the temporal cortex is positively related to severity of disease $(36,37)$.

Study of the effects of cholinergic drugs has provided information complementary to that of the post-mortem, biochemical and PET studies. In broad terms, antinicotinic drugs (e.g. mecamylamine) impair certain parameters of intellectual functioning, while cholinergic drugs such as nicotine often do the opposite (38). Interpretation of these results is difficult, however, because the effects of nicotine are dose dependent and a variety of doses and dose schedules were used in the studies. This pharmacologic evidence, along with the other evidence, has led to a cholinergic theory of AD pathogenesis. That is, the cholinergic system may be involved in attention and memory (mediated by the cortex), and that degeneration of this system may be responsible for the intellectual deficits in $\operatorname{AD}(33,39)$.

Several controlled studies have tested this cholinergic hypothesis in animals. Nicotine has in most cases been shown to improve some aspects of intellectual 
performance, although some have shown the drug to be detrimental (38). These results must be interpreted in light of nicotine's inverted- $U$ effect curve; although at lower doses a positive relationship exists between dose and performance, beyond a certain dose, the drug increasingly hinders performance (33).

Jones et al. studied the effect of subcutaneous nicotine on humans with dementia of Alzheimer's type and on normal controls (40). The drug was shown to improve several measures of performance in those with the disease. Nicotine increased motor speed as measured by a finger tapping test, decreased the amount of time spent copying a sequence of images, and increased the ability of subjects to pick a flashing light presented on a screen. This study is in accordance with others indicating that the drug increases attention and vigilance more than short-term memory (38).

Drugs with actions similar to that of nicotine with a more favorable side-effect profile are being developed. One drug developed by Abbott Laboratories (ABT-418) has been shown to modestly increase $(\sim 11 \%$ above baseline accuracy) the performance of aged monkeys in a delayed matching to sample test (41). Although nicotinic agonists are promising drugs, the only drugs widely used for the treatment of $\mathrm{AD}$ are the reversible acetylcholinesterase inhibitors. Tacrine, a member of this drug class, was shown by a large (treatment group $n=238$ ) randomized study to increase or stabilize AD patients' performance on tests of recall, word recognition, orientation, and others. Tacrine, in doses greater than $80 \mathrm{mg}$, has also been shown to delay nursing home placement $(42,43)$.

Along with organism scale effects, it has been shown recently that nicotine inhibits the aggregation of precursor $\beta$-peptides into the oligomeric $\beta$-sheets characteristic of Alzheimer's disease plaques (44). In addition, stimulation of nicotinic receptors has been shown to decrease the toxicity of $\beta$-amyloid (45). These new findings strengthen the cholinergic hypothesis in that they do not depend on a particular neuronal pathway for their action.

Thus, the cholinergic hypothesis - like the dopaminergic hypothesis associated with schizophrenia - although neither detailed nor established at a molecular level might result in a viable treatment for $\mathrm{AD}$. In the future, agonists with affinities for particular neuronal receptors may allow for directed treatment of neurodegenerative disorders.

\section{Schizophrenia}

Schizophrenia is a common disease with a reported lifetime prevalence of about $0.6-1.5 \%$ depending on the particular study and population involved (46). The schizophrenic phenotype likely has genetic underpinnings, as shown by twin/adoption studies, brought out in part by physical and psychosocial stressors (47-49). The disease is most likely oligo- or polygenetic and results in differences in brain structure (in the thalamus and other structures) (50-52).

The pathophysiology of schizophrenia is complex, but it has been hypothesized that overactivity of the brain's dopaminergic system leads to the symptoms of the disease. This explanation is supported by the observation that dopamine receptor (D2 type) blocking drugs are effective against psychotic symptoms, and that the affinity of some neuroleptics for the D2 receptor is related to their potency (53). Postmortem studies generally show more D2 receptors in the putamen and caudate of schizophrenics $(53,54)$. The dopamine hypothesis, however, cannot explain all the data. New atypical antipsychotics that bind less to D2 receptors and more to other brain receptors are very effective in treating schizophrenia, particularly the negative symptoms not alleviated by older drugs (55-57). Also, a host of other dopamine receptors including D1, D3, D4 and D5 variants have been discovered. The relationship between these proteins and schizophrenia is less apparent (58).

In addition to the dopaminergic system, aberrations in the GABAergic and glutaminergic systems may contribute to the pathogenesis of schizophrenia (58). Particular evidence includes the facts that NMDA glutamate receptor antagonists (PCP and ketamine) produce psychosis similar to that seen in those having the disease $(59,60)$, and that glutamate is decreased in the hippocampus and pre-frontal cortex of schizophrenics. Thus, the pathophysiology of schizophrenia cannot be simply explained by brainwide dopaminergic hyperactivity and other neurotransmitter systems are likely involved.

Recently the $\alpha 7 \mathrm{nAChR}$ has been implicated in some ways with the pathogenesis of schizophrenia $(61,62)$. A relationship between smoking and nicotinic receptors is suggested on clinical grounds, as schizophrenics are over 2.6 times more likely to smoke than nonschizophrenics (63). Although this excess of nicotine use may be due to socioeconomic causes, interactions with medications that schizophrenics are more likely to take, and other factors, it is not unreasonable to explore the hypothesis that persons with schizophrenia use this drug because of its actions at nicotinic receptors in the brain (64).

Initial evidence for the involvement of the $\alpha 7$ neuronal nicotinic receptor in schizophrenia has come from genetic linkage studies. This work is aided by the use of schizotactic markers, which are phenotypic elements associated with schizophrenia. Examples include eye movement dysfunction and the p50 evoked 
potential gating deficit, both of which are objectively observable, and are present in families with schizophrenia $(61,65)$. Those with schizophrenia usually have the particular marker while some with the marker do not have schizophrenia, consistent with the stressdiathesis model. It can be hypothesized that the aberration that causes schizophrenia is genetically linked with these particular markers, and therefore, linkage studies of these traits may highlight regions of particular chromosomes containing "schizophrenia" genes.

The p50 evoked potential marker involves recording the electrical responses of the medial temporal lobe (61). Using this measurement, a patient is presented with an auditory stimulus, and the evoked potential is measured via an electrode. After a fixed time, another sound is produced and the response is measured again. Normally the second potential is smaller indicating habituation. This decrease in potential is known as prepulse inhibition, and is quantified by the ratio of the two signals (the $\mathrm{t} / \mathrm{c}$ ratio). Schizophrenics and some of their clinically normal relatives have a high $\mathrm{t} / \mathrm{c}$ ratio indicating that they do not attenuate the second sound (61).

Schizophrenics have difficulty with habituation, and therefore cannot filter extraneous sounds such as the humming of an air conditioner (66). This deficit may be important in the pathogenesis of schizophrenia as patients are hypervigilant and may misinterpret such sounds as threatening. Wahlberg et al. hypothesized that "the inability to process information and to sustain focal attention selectively may...share a vulnerability substrate with disordered thought" (67). Thus, the p50 measurement may test a facet of neurophysiological deficit present in schizophrenics.

Interestingly, administration of nicotine to patients and their non-gating relatives normalizes the p50 deficit $(68,69)$. In addition, the p50 deficit has been linked to the locus $15 q 13-14$ which is near the $\alpha 7$ neuronal nAChR (70). Autoradiographic evidence supports a role for the neuronal nicotinic receptor in schizophrenia as well. Postmortem ${ }^{125} \mathrm{I}$-Btx binding studies performed on the brains of 8 schizophrenics and 8 age matched controls showed a significant decrease in $\alpha 7$ subunit density in the hippocampi of the majority of the affected individuals (70). ${ }^{3} \mathrm{H}$-cytosine binding was also significantly decreased in schizophrenics. These three lines of evidence further implicate nicotinic systems in the pathophysiology of schizophrenia, and has led to the hypothesis that nicotinic receptors activate GABAergic inhibitory pathways that suppress response to repetitive stimuli (61).

The hypothesis that the $\alpha 7 \mathrm{nAChR}$ is involved in the pathogenesis of schizophrenia - largely espoused by Freedman and his colleagues - combines physiologic, morphologic and genetic arguments to explain many of the observations in this important disease. Along with AD (as unified by the cholinergic hypothesis), schizophrenia represents a large area for nicotinic receptor based pharmacotherapeutic research.

\section{CONCLUSION}

The nicotinic acetylcholine receptor is implicated in a number of disease states. Aberrations include missense mutations, changes in gross channel density, and likely others. The goal of this review has been to describe the nAChR as a molecular machine that can misfunction in a number of ways. Changes in receptor's primary amino acid sequence that cause disease are rare and can be inherited in a Mendelian fashion. These syndromes can be described in terms of resultant changes in the biophysical properties of the channel. Neurodegenerative conditions such as schizophrenia and $\mathrm{AD}$ may involve decreases in channel density in vital parts of the brain. Therapeutic regimes involving nicotinic agonists are being developed which may ameliorate these deficits. Understanding the nature and mechanism of cholinergic dysfunction will most likely facilitate these therapeutic advances.

\section{ACKNOWLEDGEMENTS}

We would like to acknowledge the help of Drs. Anthony Auerbach and Claudio Grosman in the preparation of this review. This work was funded by a Howard Hughes Medical Institute Medical Student Fellowship to FS.

\section{REFERENCES}

1. Cooper E, Couturier S, Ballivet M. Pentameric structure and subunit stoichiometry of a neuronal nicotinic acetylcholine receptor. Nature 350: 235-238; 1991.

2. Anand R, Conroy WG, Schoepfer R, et al. Neuronal nicotinic acetylcholine receptors expressed in Xenopus oocytes have a pentameric quaternary structure. Journal of Biological Chemistry 266: 11192-11198; 1991.

3. Devillers-Thiéry A, Galzi JL, Eiselé JL, et al. Functional architecture of the nicotinic acetylcholine receptor: A prototype of ligand gated ion channels. Journal of Membrane Biology 136: 97-112; 1993.

4. Galzi JL, Devillers-Thiéry A, Hussy N, et al. Mutations in the channel domain of a neuronal nicotinic receptor converts ion selectivity from cationic to anionic. Nature 359: 500-505; 1992.

5. Devay P, Brussaard A, Listerud M, et al. Diversity in functional properties and primary structure of neuronal nicotinic receptor channels. Renal Physiology and Biochemistry 17: 172-177; 1994.

6. Gotti C, Fornasari D, Clementi F. Human neuronal nicotinic receptors. Progress in Neurobiology 53: 199-237; 1997.

7. Stauderman KA, Mahaffy LS, Akong M, et al. Characterization of human recombinant neuronal nicotinic acetylcholine receptor subunit combinations $\alpha 2 \mathrm{~b} 4, \alpha 3 \beta 4$ and $\alpha 4 \beta 4$ stably expressed in HEK293 cells. Journal of Pharmacology and Experimental Therapeutics 284: 777-789; 1998. 
8. Couturier S, Bertrand D, Matter JM, et al. A neuronal nicotinic acetylcholine receptor subunit $(\alpha 7)$ is developmentally regulated and forms a homo-oligomeric channel blocked by alpha-BTX. Neuron 5: 847-856; 1990.

9. Gotti C, Moretti M, Maggi R, et al. $\alpha 7$ and $\alpha 8$ nicotinic receptor subtypes immunopurified from chick retina have different immunological, pharmacological and functional properties. European Journal of Neuroscience 9: 1201-1211; 1997.

10. Gerzanich V, Anand R, Lindstrom J. Homomers of $\alpha 8$ and $\alpha 7$ subunits of nicotinic receptors exhibit similar channel but contrasting binding site properties. Molecular Pharmacology 45: 212-220; 1994.

11. McGehee DS, Role LW. Physiological diversity of nicotinic acetylcholine receptors expressed by vertebrate neurons. Annual Review of Physiology 57: 521-546; 1995.

12. Sivilotti L, Colquhoun D. Acetylcholine receptors: too many channels, too few functions. Science 269: 1681-1682; 1995.

13. Jackson MB. Single channel currents in the nicotinic acetylcholine receptor: a direct demonstration of allosteric transitions. Trends in Biochemical Sciences 19: 396-399; 1994.

14. Auerbach A, Akk G. Desensitization of mouse nicotinic acetylcholine receptor channels. A two-gate mechanism. Journal of General Physiology 112: 181-197; 1998.

15. Vernino S, Rogers M, Radcliffe KA, et al. Quantitative measurement of calcium flux through muscle and neuronal nicotinic acetylcholine receptors. The Journal of Neuroscience 14: 5514-5524; 1994

16. Berridge MJ, Bootman MD, Lipp P. Calcium - a life and death signal. Nature 395: 645-648; 1998.

17. Clarke PBS. Nicotinic receptors in mammalian brain: localization and relation to cholinergic innervation. Progress in Brain Research 98: 77-83; 1993.

18. Mesulam M. Cholinergic pathways and the ascending reticular activating system of the human brain. Annals of the New York Academy of Sciences 757: 169-179; 1995.

19. McGehee DS, Heath MJS, Gelber S, et al. Nicotine enhancement of fast excitatory synaptic transmission in CNS by presynaptic receptors. Science 269: 1692-1696; 1995.

20. Steinlein OK. New insights into the molecular and genetic mechanisms underlying idiopathic epilepsies. Clinical Genetics 54: 169-175; 1998.

21. Scheffer IE, Bhatia KP, Lopes-Cendes I, et al. Autosomal dominant nocturnal frontal lobe epilepsy: a distinctive clinical disorder. Brain 118: 61-73; 1995.

22. Phillips HA, Scheffer IE, Berkovic SF, et al. Localization of a gene for autosomal dominant nocturnal frontal lobe epilepsy to chromosome 20q13.2. Nature Genetics 10: 117-203; 1995.

23. Steinlein OK, Mulley JC, Propping P, et al. A missense mutation in the neuronal nicotinic acetylcholine $\alpha 4$ subunit is associated with autosomal dominant nocturnal frontal lobe epilepsy. Nature Genetics 11: 201-203; 1995.

24. Kuryatov A, Gerzanich V, Nelson M, et al. Mutation causing autosomal dominant nocturnal frontal lobe epilepsy alters $\mathrm{Ca}^{2+}$ permeability, conductance, and gating of human $\alpha 4 \beta 2$ nicotinic acetylcholine receptors. Journal of Neuroscience 17: 90359047; 1997.

25. Engel AG, Ohno K, Sine SM. Congenital myasthenic syndromes: experiments of nature. Journal of Physiology (Paris) 92: 113-117; 1998.

26. Vincent A, Newland C, Croxen R, et al. Genes at the junction candidates for congenital myasthenic syndromes. Trends in Neurosciences 20: 15-22; 1997.

27. Zhou M, Engel AG, Auerbach A. Serum choline activates mutant acetylcholine receptors that cause slow channel congenital myasthenic syndromes. Proceedings of the National
Academy of Sciences USA 96: 10466-10471; 1999.

28. Sine SM, Ohno K, Bouzat C, et al. Mutation of the acetylcholine receptor $\alpha$ subunit causes a slow-channel myasthenic syndrome by enhancing agonist binding affinity. Neuron 15: 229-239; 1995.

29. Milone M, Wang HL, Ohno K, et al. Slow-channel congenital myasthenic syndrome caused by enhanced activation, desensitization, and agonist binding affinity due to mutation in the M2 domain of the acetylcholine receptor $\alpha$ subunit. Journal of Neuroscience 17: 5651-5665; 1997.

30. Wang HL, Auerbach A, Bren N, et al. Mutation in the M1 domain of the acetylcholine receptor $\alpha$ subunit decreases the rate of agonist dissociation. Journal of General Physiology 109: 757-766; 1997.

31. Ohno K, Hutchinson DO, Milone M, et al. Congenital myasthenic syndrome caused by prolonged acetylcholine receptor channel openings due to a mutation in the M2 domain of the $\varepsilon$ subunit. Proceedings of the National Academy of Sciences USA 92: 758-762; 1995.

32. Engel AG, Ohno K, Milone M. New mutations in acetylcholine receptor subunit genes reveal heterogeneity in the slow-channel congenital myasthenic syndrome. Human Molecular Genetics 5: 1217-1227; 1996.

33. Collerton D. Cholinergic function and intellectual decline in Alzheimer's disease. Neuroscience 19: 1-28; 1986.

34. Whitehouse PJ, Martino AM, Antuono PG, et al. Nicotinic acetylcholine binding sites in Alzheimer's disease. Brain Research 371: 146-151; 1986.

35. Bird TD, Stranahan S, Sumi SM, et al. Alzheimer's disease: choline acetyltransferase activity in brain tissue from clinical and pathological subgroups. Annals of Neurology 14: 284-293; 1983.

36. Nordberg A. In vivo detection of neurotransmitter changes in Alzheimer's disease. Annals of the New York Academy of Sciences 695: 27-33; 1993.

37. Nordberg A, Lundqvist H, Hartvig P, et al. Kinetic analysis of regional $(\mathrm{S})(-)^{11} \mathrm{C}$-nicotine binding in normal and Alzheimer brains - in vivo assessment using positron emission tomography. Alzheimer Disease and Associated Disorders 9: 21-27; 1995.

38. Levin ED. Nicotinic systems and cognitive function. Psychopharmacology 108: 417-431; 1992.

39. Birtwistle J, Hall K. Does nicotine have beneficial effects in the treatment of certain diseases? British Journal of Nursing 5: 1195-1202; 1996.

40. Jones GMM, Sahakian BJ, Levy R, et al. Effects of acute subcutaneous nicotine on attention, information processing and short-term memory in Alzheimer's disease. Psychopharmacology 108: 485-494; 1992.

41. Prendergast MA, Terry AV Jr, Jackson WJ, et al. Improvement in accuracy of delayed recall in aged and non-aged mature monkeys after intramuscular or transdermal administration of the CNS nicotinic receptor agonist ABT-418. Psychopharmacology 130: 276-284; 1997.

42. Raskind MA, Sadowski CH, Sigmund WR, et al. Effect of tacrine on language, praxis, and noncognitive behavioral problems in Alzheimer disease. Archives of Neurology 54: 836840; 1997.

43. Knopman D, Schneider L, Davis K, et al. Long term tacrine (Cognex) treatment: effects on nursing home placement and mortality. Neurology 47: 166-177; 1996.

44. Salomon AR, Marcinowski KJ, Friedland RP, et al. Nicotine inhibits amyloid formation by the $\beta$-peptide. Biochemistry 35 : 13568-13578; 1996.

45. Kihara T, Shimohama S, Sawada H, et al. Nicotinic receptor 
stimulation protects neurons against beta-amyloid toxicity. Annals of Neurology 42: 159-163; 1997.

46. Häfner H, an der Heiden W. Epidemiology of schizophrenia. Canadian Journal of Psychiatry 42: 139-151; 1997.

47. Wahlberg KE, Wynne LC, Oja $\mathrm{H}$, et al. Gene-environment interaction in vulnerability to schizophrenia: findings from the Finnish adoptive study of schizophrenia. American Journal of Psychiatry 154: 355-362; 1997.

48. Susser E, Neugebauer R, Hoek H, et al. Schizophrenia after prenatal famine: further evidence. Archives of General Psychiatry 53: 25-31; 1996.

49. Jones P, Rodgers B, Murray R, Marmot M. Child developmental risk factors for adult schizophrenia in the British 1946 birth cohort. Lancet 344: 1398-1402; 1994.

50. Andreasen NC, Arndt S, Swayze V, et al. Thalamic abnormalities in schizophrenia visualized through magnetic resonance image averaging. Science 266: 294-298; 1994.

51. O'Donovan MC, Owen MJ. The molecular genetics of schizophrenia. Annals of Medicine 28: 541-546; 1996.

52. Florencio PS, O'Driscoll GA. The medial temporal lobe and schizophrenia. McGill Journal of Medicine 5: 25-34; 1999.

53. Davis KL, Kahn RS, Ko G, Davidson M. Dopamine in schizophrenia: a review and reconceptualization. American Journal of Psychiatry 148: 1474-1486; 1991.

54. Lee T, Seeman P, Tourtellotte WW, et al. Binding of ${ }^{3} \mathrm{H}-$ neuroleptics and ${ }^{3} \mathrm{H}$-apomorphine in schizophrenic brains. Nature 274: 897-900; 1978.

55. Roth BL, Meltzer HY, Khan N. Binding of typical and atypical antipsychotic drugs to multiple neurotransmitter receptors. Advances in Pharmacology 42: 482-485; 1998.

56. Iskedjian M, Hux M, Remington GJ. The Canadian experience with risperidone for the treatment of schizophrenia: an overview. Journal of Psychiatry and Neuroscience 23: 229-239; 1998.

57. Davies A, Adena MA, Keks NA, et al. Risperidone versus haloperidol: I. Meta-analysis of efficacy and safety. Clinical Therapeutics 20: 58-71; 1998.

58. Egan MF, Weinberger DR. Neurobiology of schizophrenia. Current Opinion in Neurobiology 7: 701-707; 1997.
59. Deutsch SI, Mastropaolo J, Schwartz BL, et al. A "glutamatergic hypothesis" of schizophrenia. Rationale for pharmacotherapy with glycine. Clinical Neuropharmacology 12: 1-13; 1989.

60. Tsai G, Passani LA, Slusher BS, et al. Abnormal excitatory neurotransmitter metabolism in schizophrenic brains. Archives of General Psychiatry 52: 829-836; 1995.

61. Leonard S, Adams C, Breese CR, et al. Nicotinic receptor function in schizophrenia. Schizophrenia Bulletin 22: 431-444; 1996.

62. Freedman R, Coon H, Myels-Worsley M, et al. Linkage of a neurophysiological deficit in schizophrenia to a chromosome 15 locus. Proceedings of the National Academy of Sciences of the USA 94: 587-592; 1997.

63. De Leon J, Dadvand M, Canuso C, et al. Schizophrenia and smoking: an epidemiological survey in a state hospital. American Journal of Psychiatry 152: 453-455; 1995.

64. Ziedonis DM, Kosten TR, Glazer WM, et al. Nicotine dependence and schizophrenia. Hospital and Community Psychiatry 45: 202-206; 1994.

65. Holzman PS, Kringlen E, Matthysse S, et al. A single dominant gene can account for eye tracking dysfunctions and schizophrenia in offspring of discordant twins. Archives of General Psychiatry 45: 641-647; 1988.

66. Shagass C. An electrophysiological view of schizophrenia. Biological Psychiatry 11: 3-30; 1976.

67. Wahlberg KE, Wynne LC, Oja H, et al. Gene-environment interaction in vulnerability to schizophrenia: findings from the Finnish adoptive study of schizophrenia. American Journal of Psychiatry 154: 355-362; 1997.

68. Alder LE, Hoffer L, Griffith J, et al. Normalization by nicotine of deficient auditory sensory gating in the relatives of schizophrenics. Biological Psychiatry 32: 607-616; 1992.

69. Adler LE, Hoffer L, Wiser A, et al. Normalization of auditory physiology by cigarette smoking in schizophrenic patients. American Journal of Psychiatry 150: 1856-1861; 1993.

70. Freedman R, Hall M, Adler LE, et al. Evidence in postmortem brain tissue for decreased numbers of hippocampal nicotinic receptors in schizophrenia. Biological Psychiatry 38: 22-33; 1995.

Dr. Frank Salamone is a graduate of Boston University and the SUNY at Buffalo School of Medicine. His research on the nicotinic acetylcholine receptor in Dr. Anthony Auerbach's laboratory was supported by a Howard Hughes Medical Institute Medical Student Fellowship. He is currently completing a surgical internship at the University of Cincinnati. Dr. Ming Zhou received his B.Sc. from Fudan University, Shanghai, China and his Ph.D from SUNY at Buffalo. He studied the structurefunction relationships of the nicotinic acetylcholine receptor as his Ph.D. thesis in Dr. Anthony Auerbach's lab. He is now a postdoctoral associate in the Rockefeller University. 